\title{
scripted
}

Volume 12, Issue 1, June 2015

\section{A NOTE FROM THE EDITORS}

Laura Downey* and Catriona McMillan**

DOI: $10.2966 /$ scrip.120115.1

\section{(c) $\oplus \Theta \Theta$}

EY NC ND (C) Laura Downey and Catriona McMillan 2015. This work is licensed under a Creative Commons Attribution-NonCommercial-ShareAlike 4.0 International License Please click on the link to read the terms and conditions.

* PhD Candidate, University of Edinburgh; Editor-in-Chief, SCRIPTed - A Journal of Law, Technology \& Society

** PhD Candidate, University of Edinburgh; Managing Editor, SCRIPTed - A Journal of Law, Technology \& Society 
There have been recurring themes in the issues which we have published over the years. Unsurprisingly, privacy, data control and the Internet have been recurring topics for submissions, and this issue is no exception. Two of our contributors in this, our first issue of 2015, focus upon relative anonymity online and the precarious nature of privacy. Christophe Lazaro and Daniel Le Métayer in their article, "Control Over Personal Data: True Remedy or Fairytale?" reflect on the nature of the concept of control in respect of privacy and the reality of control over data online. These issues are also prevalent in Sara Nogueira Silva and Chris Reed's analysis, "You Can't Always Get What You Want: Relative Anonymity in Cyberspace", which examines the spectrum of expected anonymity and the precarious position of "anonymity limbo" where information is capable of being identified, but not yet identified.

Over the years there have been many, sometimes obscure, contributions to the field, including an analysis section on Zombies in the second issue of 2010. Such contributions reflect the mission of the Journal to provide a platform for research which addresses particularly novel questions for consideration; equally we also strive to showcase areas which hitherto have been underdeveloped and lacking attention. Two reports appearing in this issue, written by previous SCRIPTed editors and others who have been involved in SCRIPTed over the years, provide both reflection upon the past 10 years of SCRIPTed and links to new, and previously little explored, work in the realm of law, dance and disability. Abbe Brown, Shawn Harmon and Charlotte Waelde provide an overview on their recent collaborative work with researchers from varied backgrounds - including performing artists - exploring issues pertinent to law such as copyright in choreography and the representation of the disabled dancer in law. The authors reflect on the lessons learned from this exercise including the re-framing of questions relating to the means by which the law identifies disability and how this corresponds with the ways in which disabled dancers wish to be identified and their work valued. They also point to the challenges involved in collaborative interdisciplinary projects, particularly the difficulties in "speaking the same language" between disciplines that have very different methodologies and perceptions.

SCRIPTed continues to welcome submissions on topics reflecting concerns of law, ethics, policy and social concerns for new technology; from digital technology to biotechnologies and medical innovation. As always, work of an interdisciplinary nature is greatly encouraged.

This issue also marks a change in our Editorial Board. We say goodbye to Aisling McMahon who has stepped down as Editor-in-Chief. We also welcome Catriona McMillan who will be joining us as our new Managing Editor. We would like to thank all those who have contributed to this issue and the efforts of our wider editorial board, many of whom work voluntarily, for their continued and invaluable support. 